\title{
Electronic Data Capture Management Team Documentation
}

National Cancer Institute

\section{Source}

National Cancer Institute. Electronic Data Capture Management Team Documentation. NCI Thesaurus. Code C115689.

Records detailing the individuals who have administrative and/or editing privileges in the software system that records data collected during a study or clinical trial. 